\title{
FOUR DIMENSIONAL LOGARITHMIC TRANSFORMATION INTO $\mathscr{L}_{u}$
}

\author{
FATIH NURAY AND NimET AKIN
}

Abstract. Let $t=\left(t_{m}\right)$ and $\bar{t}=\left(\bar{t}_{n}\right)$ be two null sequences in the interval $(0,1)$ and define the four dimensional logarithmic matrix $L_{t, \bar{t}}=\left(a_{m n k l}^{t, \bar{t}}\right)$ by

$$
a_{m n k l}^{t, \bar{t}}=\frac{1}{\log \left(1-t_{m}\right) \log \left(1-\bar{t}_{n}\right)} \frac{1}{(k+1)(l+1)} t_{m}^{k+1}\left(\bar{t}_{n}\right)^{l+1} .
$$

The matrix $L_{t, \bar{t}}$ determines a sequence -to-sequence variant of classicial logarithmic summability method. The aim of this paper is to study these transformations to be $\mathscr{L}_{u}-\mathscr{L}_{u}$ summability methods.

Mathematics subject classification (2010): 40B05,40C05.

Keywords and phrases: Tauberian condition, logarithmic summability, four dimensional summability method, double sequences, Pringsheim limit.

\section{REFERENCES}

[1] R. P. AGNEW,Inclusion relations among methods of summability compounded form given matrix methods, Ark. Mat. 2, (1952), 361-374.

[2] F. BAŞAR, Summability Theory and Its Applications, Bentham Science Publishers, e-books, Monographs, İstanbul, (2012).

[3] J. A. FRIDY, Absolute summability matrices that are stronger than the identity mapping, Proc. Amer. Math. Soc. 47, (1995), 112-118.

[4] J. A. FRIDY AND K. L. ROBERT, Some Tauberian theorems for Euler and Borel tummability, Intnat. J. Math. \& Math. Sci.3,4 (1980), 731-738.

[5] J. A. FRIDY, Abel transformations into $l^{1}$, Canad. Math. Bull, 25, (1982), 421-427.

[6] H. J. Hamilton, Transformations of multiple sequences, Duke Math. J., 2 (1936), 29-60.

[7] G. H. HaRdy, Divergent series, Oxford, (1949).

[8] G. H. HaRdy and J. E. LitTlewood, Theorems concerning the summability of series by Borel's exponential methods, Rend. Circ. Mat. Palermo, 41, (1916), 36-53.

[9] G. H. HaRdy And J. E. LitTlewood, On the Tauberian theorem for Borel summability, J. London Math. Soc., 18, (1943), 194-200.

[10] M. I. KADETS, On absolute, perfect, and unconditional convergences of double series in Banach spaces, Ukrainian Math. J., 49, 8 (1997), 1158-1168.

[11] M. LemmA, Logarithmic transformations into $l^{1}$, Rocky Mountain J. Math. ,28, 1 (1998), 253-266.

[12] M. Murs aleEn And S.A. Mohiuddine, Convergence Methods for Double sequences and Applications, Springer Briefs In Mathematics, 2013.

[13] R. F. PATtERSON, A theorem on entire four dimensional summability methods, Appl. Math. Comput., 219, (2013), 7777-7782.

[14] R. F. PATterson, Four dimensional matrix characterization of absolute summability, Soochow J. Math., 30, 1 (2004), 21-26.

[15] R. F. PAtTERSON, Analogues of some fundamental theorems of summability theory, Internat. J. Math. \& Math. Sci., 23, 1 (2000), 1-9.

[16] A. Pringsheim, Zur theorie der zweifach unendlichen zahlenfolgen, Math. Ann.,53, (1900), 289-32.

[17] G. M. RoBison,Divergent double sequences and series, Trans. Amer. Math. Soc., 28, (1926), 50-73. 
[18] M. Yeşilkayagil And F. BAŞAR, A note on Abel summability of double series, Numer. Funct. Anal. Optim., 38, 8 (2017), 1069-1076. 